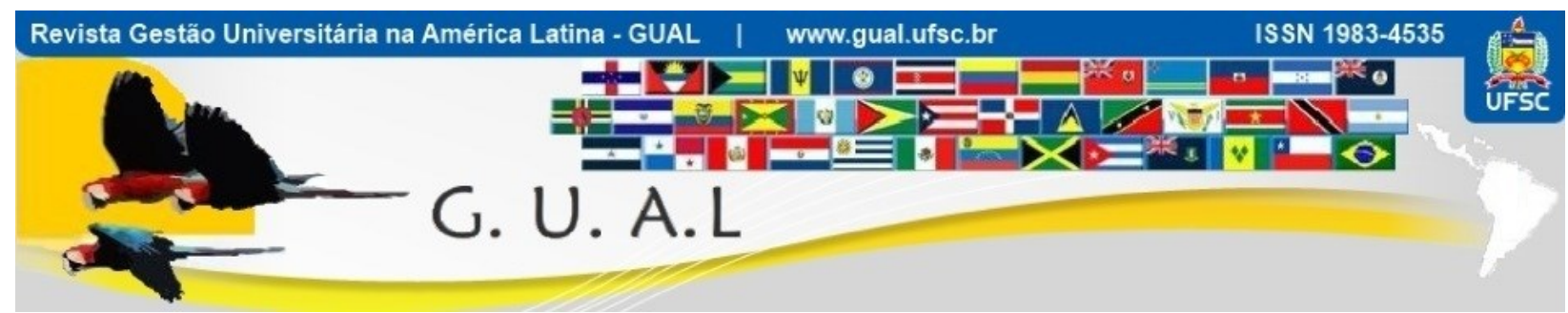

DOI: http://dx.doi.org/10.5007/1983-4535.2016v9n4p70

\title{
O DESENVOLVIMENTO DE COMPETÊNCIAS ELETRÔNICAS DOCENTES PARA EAD: UM ESTUDO EM UMA UNIVERSIDADE FEDERAL
}

\section{TEACHER'S DEVELOPMENT OF ELECTRONIC COMPETENCES FOR DISTANCE EDUCATION: A STUDY IN A FEDERAL UNIVERSITY}

Fernanda Roda de Souza Araújo Cassundé, Doutora Universidade Federal do Vale do São Francisco -UNIVASF

fernanda.roda@univasf.edu.br

José Ricardo Costa de Mendonça, Doutor Universidade Federal de Pernambuco - UFPE jrcm@ufpe.br

Milka Alves Correia Barbosa, Doutora Universidade Federal de Alagoas - UFAL milka.correia@gmail.com

Recebido em 04/dezembro/2015

Aprovado em 14/outubro/2016

Sistema de Avaliação: Double Blind Review

Esta obra está sob uma Licença Creative Commons Atribuição-Uso. 


\title{
RESUMO
}

Este estudo tem o propósito de discutir o perfil e o desenvolvimento de competências dos professores da Educação a Distância (EAD). Para o atingimento do objetivo, foi realizado um estudo qualitativo interpretativo básico. Onze professores vinculados a Universidade Federal do Vale do São Francisco (UNIVASF) e com atuação na EAD responderam as entrevistas semiestruturadas. Os dados coletados foram examinados pela análise de conteúdo proposta por Bardin (2011) com auxílio de software específico para pesquisa qualitativa, o Atlas.Ti. Disponibilidade tecnológica e interação entre os participantes foram as competências mais importantes citadas pelos professores. O desenvolvimento de tais competências, no entanto, acontece mediante o aprendizado com as próprias experiências profissionais (sejam elas docentes ou não) ou trocando experiências com seus pares. Sugere-se, para pesquisas futuras, a análise do contexto organizacional em que as necessidades e desafios específicos são definidos e em que a competência individual é desenvolvida, analisando a interferência das condições institucionais das Instituições de Ensino Superior no desenvolvimento de competências eletrônicas dos professores.

Palavras-chave: Competências eletrônicas. Educação a distância. Ensino superior.

\begin{abstract}
This study aims to discuss the profile and skills development of the Distance Education teachers. For the achievement of the objective, we conducted a basic interpretive qualitative study. Eleven teachers linked to Federal University of São Francisco Valley (UNIVASF) and operating in the distance education answered the semi-structured interviews. Data were examined by content analysis proposed by Bardin (2011) with the help of specific software for qualitative research, ATLAS.ti. Technological readiness and interaction among the participants were the most important skills cited by teachers. The development of such skills, however, happens by learning from their own professional experiences (whether teachers or not) or exchanging experiences with their peers. It is suggested, for future research, organizational context analysis in which the specific needs and challenges are defined and the individual competence is developed by analyzing the interference of institutional conditions of higher education institutions in the development of electronic skills of teachers.
\end{abstract}

Keywords: Electronic competences. Distance education. Higher education. 


\section{INTRODUÇÃO}

As instituições de ensino superior no Brasil, em virtude dos inúmeros apelos socioeconômicos e tecnológicos, têm sido incentivadas a interiorizar, a dinamizar e a aprimorar a forma de gerar e compartilhar o conhecimento.

O avanço da educação a distância (EAD) é indiscutível tanto nas instituições públicas quanto nas instituições privadas, representando a expansão de uma nova educação em concordância com a sociedade do conhecimento e as novas tecnologias.

$\mathrm{O}$ apoio que a EAD tem recebido da tecnologia, cujos instrumentos passaram a dinamizar todo o processo de ensino-aprendizagem e a tornar mais próximo o "contato" por intermédio do mundo virtual, tem mudado gradualmente o ensino superior e feito com que as instituições de ensino enfrentem a complexa tarefa de integrar a tecnologia ao contexto tradicional dos cursos (SCHNECKENBERG, 2004; 2008a; Wheeler, 2010). Na medida em que as potencialidades são viabilizadas com apoio das tecnologias de informação e comunicação (TICs), inúmeras atividades têm sido permitidas com a EAD, impactando, sobremaneira, tanto as instituições de ensino superior quanto a docência.

Nesse contexto, qualquer perspectiva de melhoria ou inovação na educação exige uma melhor capacitação dos formadores. Ou seja, essa perspectiva está ligada por uma dependência a um corpo docente altamente qualificado e atento às necessidades específicas de vários aprendizes, e que é capaz de implementar estratégias bem-sucedidas para o processo de ensino-aprendizagem. Para isso, é primordial o desenvolvimento de determinadas competências específicas (BELLONI, 2009; Ehlers; Schneckenberg, 2010; UMER; DANAHER, 2010), denominadas eletrônicas ou e-competências.

Assim, apesar de as políticas públicas para a expansão e de o desenvolvimento da EAD serem realidade para maioria das IES do país e existir consenso entre docentes e gestores de que é preciso avançar nessa modalidade de ensino para além de práticas isoladas, percebe-se ainda, em muitas delas, a falta de uma abordagem de mudança da gestão universitária para a integração das TICs ao processo de ensino-aprendizagem da EAD, mostrando que tal modalidade de ensino ainda não é compatível com as estruturas e valores atualmente existentes nas universidades (Schönwald, 2003; Schneckenberg, 2008b). Este estudo, portanto, discute o perfil de competência dos professores inseridos na EAD e a maneira através do qual tais professores buscam desenvolver essas competências. 


\section{DISCUSSÃO TEÓRICA}

Diversos são os autores que apontam que o trabalho docente no ensino superior exige o desenvolvimento de competências específicas em harmonia aos projetos individuais, institucionais e sociais (MENEZES, 2001; RAMOS, 2002; PAIVA, 2007; MENDONÇA et al, 2012b). Tais competências, do ponto de vista de Beraza (2006), devem ser constituídas por conhecimentos (conteúdos a serem ensinados, processos de ensino-aprendizagem), por habilidades específicas (comunicação, didática, métodos, processos avaliativos) e por um conjunto de atitudes próprias dos docentes enquanto formadores (disponibilidade, empatia, rigor intelectual, ética profissional, entre outras características). Corroborando com esse entendimento, Tigellar et al (2004, p.255, grifo nosso) complementam que as competências para o ensino podem ser definidas como "um conjunto integrado de características pessoais, conhecimentos, habilidades e atitudes, que são necessários para a efetiva performance em variados contextos de ensino".

Dessa feita, quando a profissão do professor passa a ser compreendida enquanto práticas associadas ao ato de ensinar, adquire características específicas (e distintas) de quaisquer outras atividades e/ou funções desempenhadas pelos professores do ensino superior, demandando, portanto, competências próprias e diferenciadas para tal (BERAZA, 2006; GILBERTO, 2013). Em Schneckenberg (2007), é possível encontrar uma classificação mais detalhada das competências docentes para o ensino superior, frequentemente utilizadas nas pesquisas sobre o tema, conforme descrito por Mendonça et al (2012a), e que estão apresentadas no Quadro 1.

\begin{tabular}{|l|l|}
\hline Tipo de competência & \multicolumn{1}{c|}{ Atributos da competência } \\
\hline \multirow{3}{*}{ Conteúdo específico } & $\begin{array}{l}\text { - Solução de problemas na área tema } \\
\text { - Conhecimento qualificado } \\
\text { - Conhecimento valorizado }\end{array}$ \\
\hline \multirow{3}{*}{ Metodológica } & $\begin{array}{l}\text { - Planejamento criativo de métodos em tarefas e soluções } \\
\text { - Aplicação eficiente de métodos em tarefas e soluções } \\
\text { - Estruturação eficiente de procedimentos cognitivos }\end{array}$ \\
\hline \multirow{2}{*}{ Social } & $\begin{array}{l}\text { - Comunicação, cooperação e interação eficiente dentro do grupo } \\
\text { - Comportamento adequado de acordo com as orientações coletivas }\end{array}$ \\
\hline \multirow{5}{*}{ Pessoal } & $\begin{array}{l}\text { - Auto avaliação crítica } \\
\text { - Desenvolvimento de atitudes, orientação para valores, motivos e auto percepção } \\
\text { produtivas e positivas } \\
\text { - Revelar talento pessoal, motivação e ambição } \\
\text { - Aprender a desenvolver-se dentro e além do contexto de trabalho }\end{array}$ \\
\hline
\end{tabular}

Quadro 1 Classificação das competências docentes para o ensino superior. Fonte: Schneckenberg (2007, p.83). 
Com base nessa classificação, Erpenbeck e Heyse (1999), citados por Schneckenberg (2007), combinam os quatro tipos de competências em um modelo integrador de competências e ações, e isso inclui a capacidade de integrar um conjunto de competências (conteúdos específicos, metodológica, social e pessoal) dentro de um processo de desempenho individual.

Ao se considerar, entretanto, o novo contexto educacional estabelecido pelo avanço tecnológico, pelo estímulo ao uso das TICs e pela consolidação da EAD, "acredita-se ser de fundamental importância a consideração de competências tecnológicas no exercício da profissão docente" (MENDONÇA et al, 2012a, p.7).

Assim, os professores, além de reforçarem as competências que já possuem, precisam, também adquirir novas competências que lhes permitam conhecer e julgar por que, quando e como utilizar as TIC na educação (Schneckenberg, 2010b; VOLK; KELLER, 2010). Isso porque a EAD em muito difere no tempo e espaço da tradicional educação presencial, e o professor passa a ser um mediador no acesso à informação durante o processo de ensinoaprendizagem, exigindo desse profissional novas competências, uma vez que ele precisa ser sensibilizado e preparado para utilizar todo o potencial educativo das tecnologias disponíveis para a EAD e, assim, provavelmente, novos saberes vão sendo construídos (HARRY; DESMOND; JONH, 2006; ARRUDA, 2007; MARTINS, 2008; SANAVRIA, 2008; SOUZA; SARTORI; ROESLER, 2008; Jakobsdóttir; McKeown; Hoven, 2010; VOLK; KELLER, 2010; GILBERTO, 2013). Paiva (2007) acrescenta que os avanços tecnológicos afetam diretamente o professor, permanecendo como um ponto questionável de sua atividade, uma vez que "a revolução tecnológica está produzindo 'a fórceps' uma nova profissionalidade docente" (CUNHA, 2001, p.87).

Quando inseridos na EAD, os professores têm que ser capazes de reconhecer as limitações e o potencial da tecnologia, bem como as melhores técnicas para a comunicação por meio dessa tecnologia, reformulando práticas pedagógicas de modo a possibilitar a criação de novas experiências (SOUZA; SARTORI; ROESLER, 2008; TORRES; MARRIOT; MATOS, 2009; VOLK; KELLER, 2010; MOORE; KEARSLEY, 2011), e para isso, novas competências precisam ser desenvolvidas, pois o docente na EAD desempenha papéis de outras complexidades.

Uma análise dos referenciais de qualidade para cursos de ensino superior a distância do MEC (BRASIL, 2007) sinalizam indicadores que permitem a compreensão das 
particularidades na formação do professor que atua em cursos a distância. As competências eletrônicas, portanto, não incluem apenas os aspectos técnicos, mas também a visão mais ampliada sobre a capacidade educativa para a utilização das TIC no ensino e aprendizagem (Schneckenberg, 2010b; VOLK; KELLER, 2010; Gilberto, 2013).

O fato é que o ensino na modalidade a distância é um desafio para a maioria dos docentes, exemplificam Moore e Kearsley (2011), especialmente por esse ser intermediado por uma tecnologia, permeando as práticas pedagógicas na EAD. Mesmo que os professores do ensino superior não tenham passado por um treinamento formal para exercer a regência na modalidade presencial, a maioria consegue moldar seu comportamento em sala de aula com base nos professores que teve enquanto foi aluno. Porém, até recentemente, dificilmente, uma "pessoa havia tido experiência ou recebido treinamento sobre como ensinar usando a tecnologia. As pessoas que se tornam instrutores na EAD [...] precisam aprender, desempenhando as funções com quase nenhuma orientação" (p.147), ou seja, os professores, geralmente, deparam-se com situações não vivenciadas anteriormente enquanto aluno, uma vez que a maioria se formou no ensino presencial (SOUZA; SARTORI; ROESLER, 2008; GILBERTO, 2013). Outros autores (Schneckenberg, 2008a; LATCHEN, 2010) também corroboram essa ideia ao afirmarem que são poucos os cursos que preparam os professores para a EAD, especialmente no que se refere às questões pedagógicas associadas às TICs. $\mathrm{O}$ que se percebe, portanto, muitas vezes, é uma formação inadequada dos professores justamente para integração das TICs aos processos de ensino.

O professor, quando entra em contato com a EAD, como caracterizam Souza, Sartori e Roesler (2008, p.329),

passa a se confrontar tempos e espaços organizados de uma forma diferente; estabelece um contato com os alunos sem contar com os olhares e gestos e, em várias situações, sem ter uma reação imediata sobre o que foi apresentado e proposto. Estes elementos implicam em um conjunto de saberes didáticopedagógicos 'novos', que, em muitos casos, colocam em xeque encaminhamentos dados para situações presenciais.

Essas circunstâncias reforçam, portanto, a necessidade do desenvolvimento de competências específicas (LATCHEN, 2010), as chamadas competências eletrônicas, para o docente atuar na EAD, pois essa modalidade tem proporcionado modelos de ensino inovadores e cada vez mais vem ganhando espaço em cursos de graduação e pós-graduação no país. 
Mendonça et al (2012b) apresentam um quadro resumo com a classificação, atributos e sustentação das competências-chave do professor em EAD (quadro 4 abaixo). Este quadro foi elaborado a partir da síntese das contribuições de Schneckenberg (2007) e Konrath, Tarouco e Behar (2009), fundamentada na classificação de Schneckenberg (2007), analisada à luz do modelo de Cheetham e Chivers (1996, 1998, 2000) adaptado por Paiva (2007).

\begin{tabular}{|c|c|c|}
\hline Tipo de competência & Atributos da competência & $\begin{array}{c}\text { Principais componentes das } \\
\text { competências que sustentam a } \\
\text { ação } \\
\end{array}$ \\
\hline \multirow{3}{*}{ Conteúdo específico } & Solução de problemas na área tema & Funcional \\
\hline & Conhecimento qualificado & Cognitiva \\
\hline & Conhecimento valorizado & Cognitiva \\
\hline \multirow{3}{*}{ Metodológica } & $\begin{array}{l}\text { Planejamento criativo de métodos em } \\
\text { tarefas e soluções }\end{array}$ & Cognitiva, funcional \\
\hline & $\begin{array}{l}\text { Aplicação eficiente de métodos em tarefas e } \\
\text { soluções }\end{array}$ & Cognitiva, funcional \\
\hline & $\begin{array}{l}\text { Estruturação eficiente de procedimentos } \\
\text { cognitivos }\end{array}$ & Cognitiva, funcional \\
\hline \multirow{2}{*}{ Social } & $\begin{array}{l}\text { Comunicação, cooperação e interação } \\
\text { eficiente dentro do grupo }\end{array}$ & Comportamental \\
\hline & $\begin{array}{l}\text { Comportamento adequado de acordo com as } \\
\text { orientações coletivas }\end{array}$ & Comportamental, ética \\
\hline \multirow{4}{*}{ Pessoal } & Autoavaliação crítica & Funcional, ética \\
\hline & $\begin{array}{l}\text { Desenvolvimento de atitudes, orientação } \\
\text { para valores, motivos e autopercepção } \\
\text { produtivas e positivas }\end{array}$ & Funcional, ética \\
\hline & $\begin{array}{l}\text { Revelar talento pessoal, motivação e } \\
\text { ambição }\end{array}$ & Comportamental, política \\
\hline & $\begin{array}{l}\text { Aprender a desenvolver-se dentro e além do } \\
\text { contexto de trabalho }\end{array}$ & $\begin{array}{l}\text { Cognitiva, funcional, } \\
\text { comportamental }\end{array}$ \\
\hline
\end{tabular}

Quadro 2 Classificação, atributos e sustentação das competências-chave do professor em EAD. Fonte: Mendonça et al (2012b, p.10).

No entendimento de Schneckenberg (2007, 2010b), as competências eletrônicas significam um dos aspectos de um debate mais amplo sobre os modelos que permitem a integração de novas tecnologias às universidades, tendo em vista que um novo contexto eletrônico está paulatinamente envolvendo e modificando o ambiente de trabalho do docente no ensino superior. Embora as competências eletrônicas tenham um foco tecnológico, salienta o autor $(2006,2010 b)$, as competências necessárias para o docente não se limitam apenas ao componente eletrônico. Não se está lidando com o nível de conhecimento de cada professor sobre aplicativos e softwares específicos, é algo mais amplo. Diz respeito às competências educacionais que necessitam para fazer julgamentos adequados para integração efetiva das TICs no processo de ensino-aprendizagem. 
Nesse sentido, em Schneckenberg (2007) é possível encontrar o esclarecimento de Euler (2004) sobre os três passos que devem ser considerados em uma abordagem baseada no contexto para que seja possível definir perfis de competências eletrônicas para contextos específicos de EAD (figura 1).

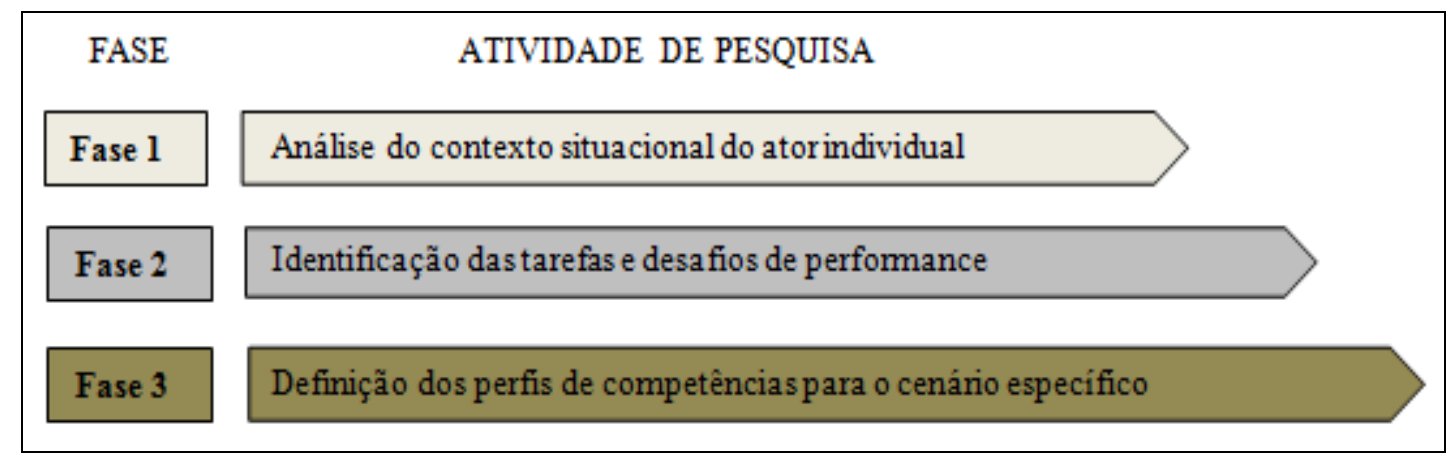

Figura 1 Fases na definição dos perfis de competências.

Fonte: Schneckenberg, 2007, p.96.

Schneckenberg (2007) argumenta que o estabelecimento de perfis de competências eletrônicas para contextos específicos começa com uma análise do contexto situacional para o qual as competências específicas devem ser desenvolvidas. Os desafios que estão incluídos nesse contexto precisam ser identificados e descritos. Essas especificações são base para uma definição dos perfis de competências que os sujeitos têm de trazer para lidarem adequadamente com os desafios situacionais e resolverem eficientemente as tarefas em situações específicas.

Nesse sentido, faz-se necessário compreender que a dinâmica do processo ensinoaprendizagem, quando intermediada pelas TICs, difere quando comparada com a modalidade presencial, especialmente com relação aos papéis e às competências do professor e também dos alunos, à nova realidade da sala de aula (que passa a ser virtual, interativa e tecnológica) e a um novo currículo no contexto de aprendizagem aberta. A eficiência desse processo (de ensino-aprendizagem) depende diretamente do ambiente de aprendizagem em que professores e alunos estão situados que, por sua vez, depende em grande parte do ajuste das competências eletrônicas dos docentes neste cenário (Schneckenberg, 2007).

Sobre os cenários de aprendizagem, o entendimento de Schneckenberg (2007) é que eles podem sofrer melhoras e ajustes pelas TICs em função de quatro elementos essenciais: a tecnologia; a forma como ela é usada e integrada aos ambientes de aprendizagem (o design); 


\section{O DESENVOLVIMENTO DE COMPETÊNCIAS ELETRÔNICAS DOCENTES PARA EAD: UM ESTUDO \\ EM UMA UNIVERSIDADE FEDERAL \\ DOI: http://dx.doi.org/10.5007/1983-4535.2016v9n4p70}

as habilidades de aprendizagem, disposição e competências dos alunos (individualmente ou em grupo); e o conteúdo a ser ensinado e aprendido.

Schneckenberg e Wildt (2006) definiram um modelo de sinergia para competências eletrônicas, a partir da identificação dos seguintes componentes principais: o professor universitário (com competência individual específica definida a partir de sua disposição para ação de forma adequada); os cenários de ensino e aprendizagem (que incorporam ou se baseiam na utilização das TICs em um contexto particular em que o desempenho do professor universitário está situado) e os alunos que interagem com o professor em momento específico no cenário de aprendizagem (a principal diferença entre o professor e os estudantes não está contida na dimensão cognitiva, mas na dimensão de desempenho. $\mathrm{O}$ objetivo principal do professor é ensinar; o objetivo principal do aluno é aprender).

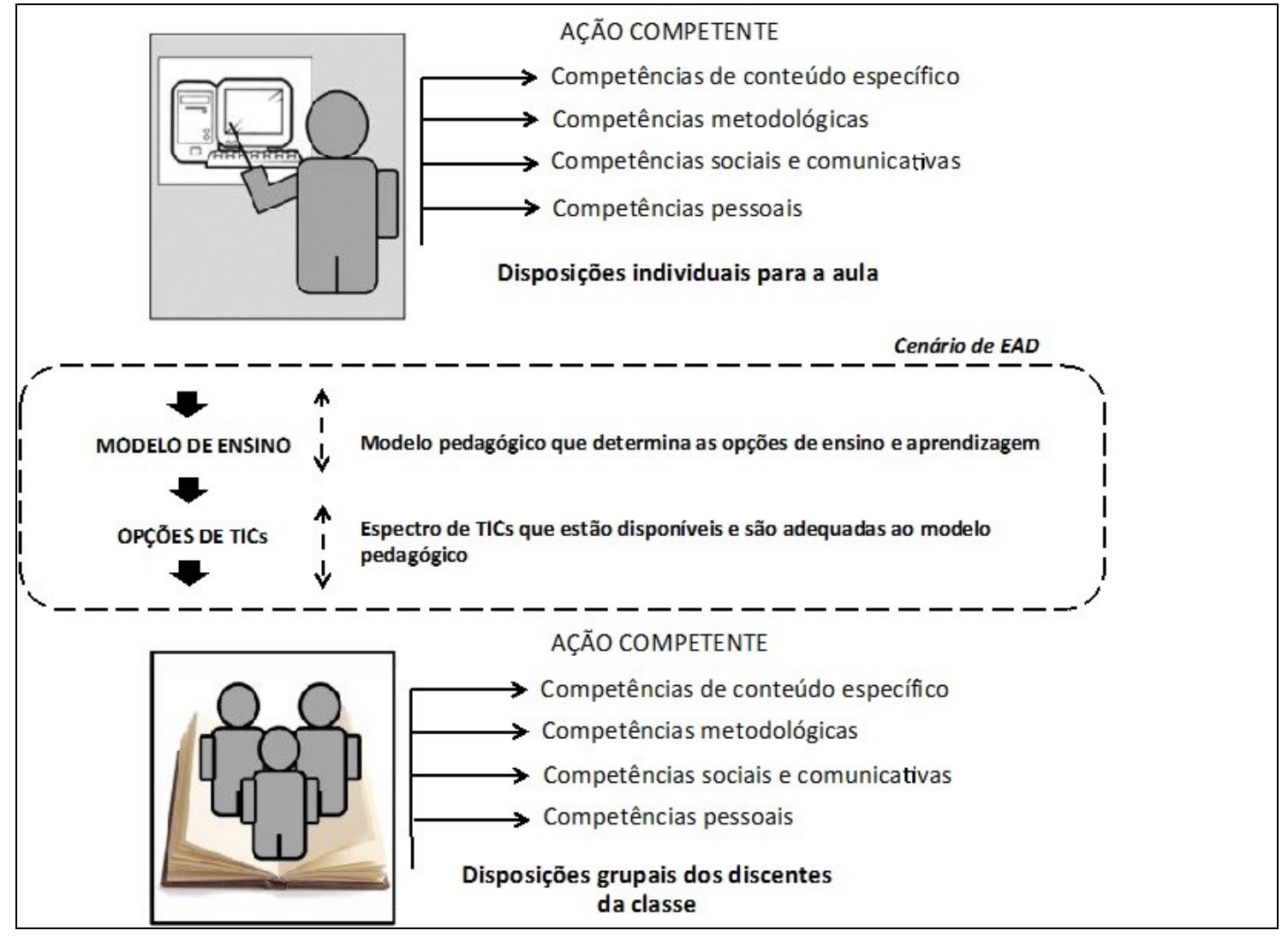

Figura 2 Modelo de sinergia para competências eletrônicas.

Fonte: Schneckenberg e Wildt (2006, p.33).

Mendonça et al (2012b) incluíram a competência avaliativa na relação de competências individuais dos professores, sugerindo, assim, uma adaptação a esse modelo. 


\begin{tabular}{|l|l|l|}
\hline \multirow{2}{*}{ Tipo de competência } & \multicolumn{1}{|c|}{ Atributos da competência } & \multicolumn{1}{|c|}{$\begin{array}{c}\text { Principais componentes das } \\
\text { competências que sustentam a ação }\end{array}$} \\
\hline \multirow{2}{*}{ Avaliativa } & $\begin{array}{l}\text { Monitorar e acompanhar a aprendizagem, } \\
\text { notificando o aluno }\end{array}$ & Cognitiva, funcional, ética \\
\cline { 2 - 3 } & $\begin{array}{l}\text { Monitorar e acompanhar a eficácia das } \\
\text { atividades do curso, notificando as instâncias } \\
\text { responsáveis }\end{array}$ & Funcional \\
\hline
\end{tabular}

Quadro 3 Classificação, atributos e sustentação das competências-chave do professor em EAD, incluindo a competência avaliativa.

Fonte: Adaptado de Mendonça et al (2012b, p.10).

\section{DESIGN DE PESQUISA}

Considerando os objetivos propostos neste estudo, entende-se que a abordagem qualitativa tanto na coleta quanto análise dos dados é a mais apropriada para a condução da pesquisa.

Como estratégia de pesquisa qualitativa, optou-se pelo estudo qualitativo interpretativo básico ou genérico, como frequentemente é rotulado na literatura, segundo Merriam (1998; 2002).

Um estudo qualitativo interpretativo básico, conforme descrevem Merriam (1998; 2002), Caelli, Ray e Mill (2003); Godoy (2005) e Stake (2005), exemplifica todas as características da pesquisa qualitativa, isto é, o pesquisador está interessado em compreender como os sujeitos dão sentido a uma situação ou fenômeno. Esse significado é mediado pelo pesquisador, a estratégia é indutiva, e o resultado é descritivo.

Foi escolhido como lócus deste estudo uma universidade federal (a Universidade Federal do Vale do São Francisco - UNIVASF) e, como unidade de análise, o curso de especialização em Gestão Pública do PNAP. É importante salientar que a escolha por essa IFES (Instituição Federal de Ensino Superior) considerou o critério de acessibilidade dos pesquisadores, do impacto regional, local e nacional, bem como a participação no Projeto PróADM - Capacitação Docente para EAD, financiado pela CAPES em edital específico. A área de Administração foi a escolhida em função de seu destaque na atuação em atividades de EAD (CASSUNDÉ; CASSUNDÉ JUNIOR, 2012; PADILHA; HELAL; MENDONÇA, 2012), inclusive sendo o curso piloto de graduação em Administração responsável por inaugurar, efetivamente, a UAB em 2006 (SILVA et al, 2012).

Para viabilização deste estudo, optou-se pelo uso da entrevista semiestruturada individual. Esse tipo de entrevista caracteriza-se pela elaboração de um roteiro, mas permite ao pesquisador ter "flexibilidade para ordenar e formular as perguntas durante a entrevista" 
(GODOI; MATTOS, 2006, p.304). O principal objetivo na realização das entrevistas é compreender os significados que os sujeitos selecionados atribuem às questões e situações relativas ao objeto de estudo. Esse tipo de entrevista pareceu ser mais adequado em função do desejo de "apreender a compreensão do mundo do entrevistado e as elaborações que ele usa para fundamentar suas opiniões e crenças" (GODOY, 2006, p.134).

Considerando que a pesquisa qualitativa busca entender o significado de um fenômeno a partir das perspectivas de seus sujeitos e que a "representatividade não é um princípio de seleção de dados" (BAUER; AARTS, 2002, p.54), torna-se importante selecionar casos ricos em informação para o estudo em profundidade, ou seja, aqueles casos a partir dos quais se pode aprender muito sobre questões de fundamental importância para o objetivo da pesquisa, caracterizando, portanto, uma seleção intencional ou proposital (MERRIAM, 2002).

Assim, para determinar o corpus de análise, Merriam (2002) sugere que é necessário inicialmente estabelecer os critérios essenciais na escolha de quem deve ser entrevistado. $\mathrm{O}$ quadro 4, a seguir, apresenta os critérios definidos para este estudo e, consequentemente, a definição dos sujeitos, considerando o lócus e o objeto de estudo.

\begin{tabular}{|l|l|l|}
\hline \multicolumn{1}{|c|}{ Critério de seleção } & \multicolumn{1}{|c|}{ Características } & \multicolumn{1}{c|}{ Sujeitos } \\
\hline \multirow{2}{*}{$\begin{array}{l}\text { Atores inseridos na prática } \\
\text { educacional }\end{array}$} & $\begin{array}{l}\text { Atores que vivenciam a prática } \\
\text { docente a partir das condições } \\
\text { impostas pela instituição. }\end{array}$ & $\begin{array}{l}\text { Docentes vinculados ao Programa } \\
\text { Nacional de Formação em } \\
\text { Administração Pública no curso de } \\
\text { Gestão Pública. }\end{array}$ \\
\hline
\end{tabular}

Quadro 4 Definição de critérios para seleção do corpus.

Fonte: Elaborado pelos autores (2015).

Os sujeitos que compuseram o grupo de respondentes foram os servidores vinculados à UNIVASF da que estavam vinculados, à época, ao Programa Nacional de Formação em Administração Pública no curso de Gestão Pública. O grupo de respondentes, a quantidade prevista (total de sujeitos) de entrevistas e a quantidade de entrevistas realizadas estão apresentados na tabela 1 .

Tabela 1 Grupo de entrevistados.

\begin{tabular}{ccc}
\hline Perfil do Entrevistado & Quantidade prevista & Entrevistas realizadas \\
\hline Coordenadores & 03 & 03 \\
Professores & 11 & 08 \\
TOTAL & 14 & 11 \\
\hline
\end{tabular}

Fonte: Elaborado pelos autores (2015). 


\section{O DESENVOLVIMENTO DE COMPETÊNCIAS ELETRÔNICAS DOCENTES PARA EAD: UM ESTUDO \\ EM UMA UNIVERSIDADE FEDERAL \\ DOI: http://dx.doi.org/10.5007/1983-4535.2016v9n4p70}

A fim de garantir a confidencialidade dos respondentes, foram atribuídos códigos de referência para identificá-los durante a transcrição de suas falas na análise de dados. O critério de julgamento para o encerramento da coleta de dados deste estudo foi o da saturação teórica que, de acordo com Bauer e Aarts (2002) e Godoi e Mattos (2006), sugere rigor ao processo de pesquisa qualitativa.

Considerando os objetivos e as técnicas de coleta de dados propostos neste estudo, entende-se que o procedimento mais adequado para a análise dos dados é a Análise de Conteúdo. Quando a Análise de Conteúdo é escolhida como mais adequada para os procedimentos de análise, no ponto de vista de Mozatto e Grzybovski (2011), os dados em si são tidos apenas como dados brutos, só apresentando algum tipo de sentido ou valor após serem trabalhados com alguma técnica de análise apropriada. Nesse sentido, este estudo utilizou a Análise Categorial, que é uma das técnicas mais utilizadas e conhecidas da Análise de Conteúdo proposta por Bardin (2011) e que, nos últimos anos, vem se destacando entre os métodos qualitativos de análise, ganhando legitimidade e sendo amplamente reconhecida no campo da produção científica em Administração (Mozatto; Grzybovski, 2011).

Com o propósito de garantir maior confiabilidade à análise e proceder a uma interpretação mais qualitativa, na qual o pesquisador prende-se às nuanças de sentido que existem entre as unidades, foi utilizada a estratégia de análise de emparelhamento. Essa estratégia pressupõe a associação dos dados recolhidos a um modelo teórico, possibilitando a comparação, ou seja, "essa estratégia supõe a presença de uma teoria forte na qual o pesquisador se fundamenta para imaginar um modelo de fenômeno ou da situação investigada" (LAVILLE; DIONNE, 1999, p. 227).

Considerando a legitimidade e a crescente utilização de softwares como apoio para análise do material empírico em pesquisas qualitativas (BANDEIRA-DE-MELLO, 2006; MAIETTA, 2008), o software ATLAS.ti ofereceu suporte a esta etapa da pesquisa.

\section{DISCUSSÃO DOS RESULTADOS}

Um perfil pode ser traçado a partir das entrevistas realizadas com os professores. A faixa etária dos docentes compreende entre 31 e 56 anos; a maioria é do sexo masculino e está em processo de capacitação (cursando mestrado ou doutorado). Dos docentes que atuaram na EAD, sete são professores de carreira da universidade e quatro são técnicos administrativos. Apesar de estarem atuando na EAD, chama a atenção o fato de apenas três dos professores 
(técnicos administrativos) terem tido contato anterior com a EAD, uma vez que o curso de especialização que fizeram foi nesta modalidade de ensino. Todos os outros professores tiveram suas formações estritamente presenciais. Sobre a experiência na docência na EAD, apenas um professor mencionou ter tido contato prévio com EAD em outra instituição. Para todos os outros, esta foi a primeira experiência com a docência no ensino a distância. Excetuando-se a coordenadora do curso, que possui uma experiência de 19 anos no ensino superior, todos os outros professores de carreira têm, em média, dez anos de experiência docente. Já os técnicos apresentam uma experiência média de ensino superior de quatro anos.

O quadro 5 abaixo apresenta os dados relativos ao perfil dos professores entrevistados.

\begin{tabular}{|r|l|}
\hline \multicolumn{1}{|c|}{ Variável } & \multicolumn{1}{|c|}{ Moda } \\
\hline Sexo & Masculino \\
\hline Idade & $31-36$ \\
\hline Vínculo com a UNIVASF & Professor de carreira \\
\hline Formação & Em processo de doutoramento \\
\hline Modalidade da formação & Estritamente presencial \\
\hline Função no curso & Professor \\
\hline
\end{tabular}

Quadro 5 Perfil dos professores entrevistados.

Fonte: Elaborado pelos autores (2015).

As competências para o ensino podem ser definidas como "um conjunto integrado de características pessoais, conhecimentos, habilidades e atitudes que são necessários para a efetiva performance em variados contextos de ensino" (TIGELLAR et al 2004, p.255). Nesse sentido, os entrevistados apontaram que as principais competências que o professor de ensino superior com atuação na EAD precisa desenvolver são: competência tecnológica; capacidade de interação com pessoas; planejamento e organização; disponibilidade de tempo; conhecimento teórico específico; e competência didática.

O resultado pode ser visualizado por meio de uma teia na Figura 3.

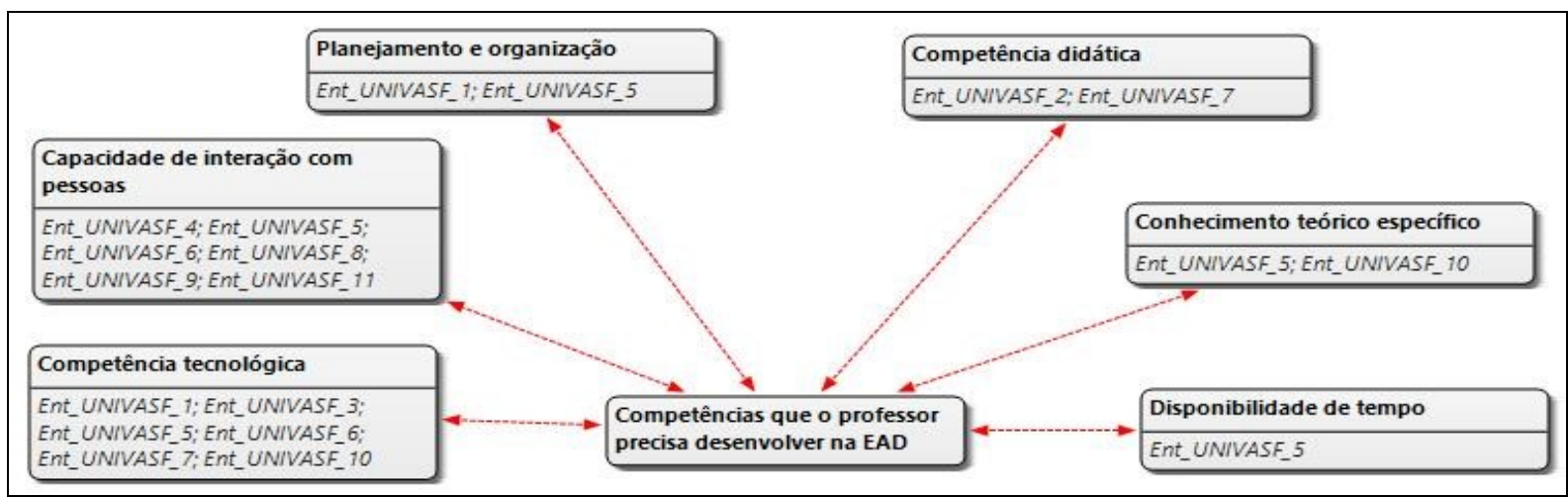

Figura 3 Teia das competências docentes para EAD.

Fonte: Elaborado pelos autores (2015). 
Uma competência bem sinalizada pelos professores foi a da disponibilidade tecnológica. A EAD, nos últimos anos, tem recebido um apoio da tecnologia e, com isso, mudado gradualmente a forma como o ensino superior é feito (SCHNECKENBERG, 2004; 2008a; Wheeler, 2010). Por isso, para os respondentes, não existe a possibilidade do vínculo com a modalidade a distância sem o conhecimento básico e sem afinidade com a tecnologia, uma vez que ela é quem viabiliza todo o processo. Assim, é correto a relação de que "a EAD está intrinsecamente ligada às TICs" definida pelos professores entrevistados (FORMIGA, 2009, p.39). Nesse sentido, a EAD ainda parece ser um desafio para a maioria dos docentes, especialmente porque é intermediada por uma tecnologia que permeia as práticas pedagógicas (MOORE; KEARSLEY, 2011).

Os trechos das entrevistas que seguem descrevem este contexto.

O que precisa desenvolver mais atualmente é mídia, né. De mídia. Porque é uma diferença muito grande em você ser professor presencial e você ser professor a distância, por conta do domínio da mídia.

Ent_UNIVASF_3

Tem que gostar de internet. Se você não gostar de computador, se você não gostar de mexer com coisa eletrônicas, não vá, porque seu trabalho todo vai ser dependendo dessa ferramenta, desse meio....

Ent_UNIVASF_5

De imediato eu não consigo dissociar o ensino a distância da competência em tecnologia.

Ent_UNIVASF_6

Não tem como você desenvolver um trabalho bom em EAD se não for se apropriando de tecnologia de informação.

Ent_UNIVASF_10

Chama a atenção também o fato de os professores estarem preocupados com a questão da interação e terem consciência de que essa é uma competência importante na educação a distância, tendo em vista que o plano em que trabalham professores e alunos, muitas vezes, é assíncrono, ou seja, os alunos de educação a distância estão afastados de seus professores em termos de espaço e/ou tempo (MOORE; KEARSLEY, 2011). É possível perceber isso nas falas que se seguem.

Tem que gostar de trabalhar com pessoas que tenham um perfil bastante diferente, porque a EAD vai trazer isso. [...] É a coisa do seguir a turma, do conhecer a turma, de ter essa disponibilidade (de interação).

Ent_UNIVASF_5

Uma outra competência que eu acho que precisa ter, mas não sei como aprimorar isso, é a relação dele, a forma dele lidar com as pessoas, porque a EAD exige do 
professor um traquejo, uma habilidade de lidar com o outro, seja o coordenador, o tutor e, principalmente os alunos, e ela não está em segundo plano, está emparelhada com a primeira, é ele ter ciência que ele vai se relacionar com pessoas que, por estar na modalidade a distância, eles precisam ver esse relacionamento de maneira diferente.

Ent_UNIVASF_6

Tais achados apoiam a visão de diversos autores, uma vez que esta distância geográfica implica a interação entre professores e alunos por intermédio dos Ambientes Virtuais de Aprendizagem (AVAs) e de uma elevada dependência das TICs (SCHÖNWALD, 2003; BARBOSA; REZENDE, 2006; RIBEIRO; TIMM; ZARO, 2007; SCHNECKENBERG, 2007; 2008b; SANAVRIA, 2008; MOORE; KEARSLEY, 2010; WROBEL et al, 2010; MENDONÇA et al, 2012b). Assim, a interação na educação a distância, conforme Moore e Kearsley (2011, p.241), refere-se, essencialmente, a "interrelação das pessoas, que são professores e alunos, nos ambientes que possuem a característica especial de estarem separados entre si”. Nesse sentido, Mattar (2009) alerta para o fato de que a interação não ocorre sozinha; ela precisa ser planejada, o que implica investimentos de tempo e, especialmente, treinamento. Os professores que vão atuar na EAD precisam ser treinados e capacitados para compreenderem a usabilidade da tecnologia com que vão trabalhar, ressalta o autor.

Ao comparar as competências elencadas pelos professores com o conjunto de competências estabelecido na ação competente do professor no modelo integrado para o desenvolvimento das competências dos professores e discentes a partir das dimensões para a implementação da EAD em contextos universitários, apresentado na Figura 3, percebe-se que os professores destacam a importância para as competências metodológicas, de conteúdo específico, pessoais e sociais e comunicacionais, conforme a teia representada na Figura 4. Os professores parecem não considerar, embora sejam tão importantes quanto as outras, as competências avaliativas para o desempenho na EAD. Desse modo, é preciso considerar que as competências eletrônicas necessárias para a atuação na EAD não são relativas apenas aos aspectos técnicos, ou seja, elas precisam desenvolver uma visão mais ampliada sobre a capacidade educativa para a utilização das TIC no ensino e aprendizagem (STALMEIER, 2006; Schneckenberg, 2010b; VOLK; KELLER, 2010; Gilberto, 2013). 


\section{O DESENVOLVIMENTO DE COMPETÊNCIAS ELETRÔNICAS DOCENTES PARA EAD: UM ESTUDO \\ EM UMA UNIVERSIDADE FEDERAL \\ DOI: http://dx.doi.org/10.5007/1983-4535.2016v9n4p70}

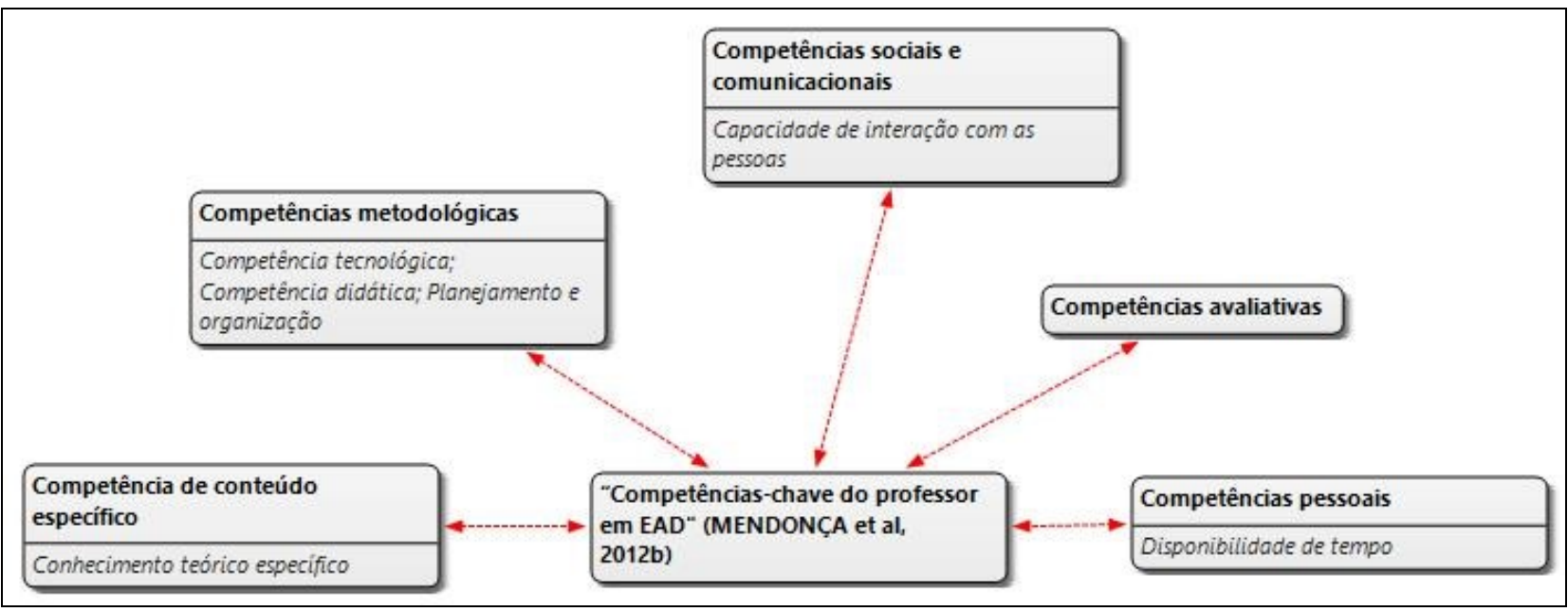

Figura 4 Teia das competências-chave do professor em EAD UNIVASF.

Fonte: Elaborado pelos autores (2015).

Questionou-se, então, como os professores procuram desenvolver tais competências por eles elencadas no dia a dia no sentido de se preparar para atuar na modalidade a distância, uma vez que, segundo Schneckenberg (2010a), o desenvolvimento de competências pelo corpo docente inclui medidas e incentivos formais e informais mais amplos para a atuação na EAD porque o professor é considerado um elemento imprescindível para o sucesso da aprendizagem e, por isso, é fundamental que esteja bem preparado, que conheça as tecnologias sem limitar-se ao tecnicismo (GILBERTO, 2013).

Os professores entrevistados, então, sinalizam que desenvolvem as competências necessárias para atuação na EAD mediante o aprendizado com as próprias experiências profissionais (sejam elas docentes ou não) ou trocando experiências com seus pares. Eles salientam que é importante o professor conhecer a dinâmica do ensino a distância, de como o aluno deve se comportar. Assim, chama-se a atenção para o fato de os entrevistados Ent_UNIVASF_2 e Ent_UNIVASF_3 terem buscado realizar um curso na modalidade EAD para poder entender o funcionamento dessa modalidade enquanto aluno e, assim, compreender as necessidades e angústias dos discentes na EAD. Seguem as falas dos entrevistados.

Quando você é professor e nunca foi aluno a distância eu acho mais complicado, quando você faz primeiro uma disciplina ou curso a distância, facilita. Então, para mim foi fácil, tanto a montagem do material, como lançar na plataforma, fóruns, atividades, bem tranquilo, porque quando eu fiz a minha especialização eu fiz a distância, então eu vi o lado do aluno.

Ent_UNIVASF_2 
$\mathrm{Eu}$, antes de entrar na $\mathrm{EAD}$, eu resolvi fazer um curso a distância para saber como era. Então eu fiz laboratório. Pra mim aquele curso foi só laboratório. Tanto que eu fiz o curso e nunca fui buscar o certificado. Porque me interessava fazer $o$ laboratório, de como seria ser um aluno a distância. Como é que tem que se comportar o aluno. Quais são as dificuldades do aluno.

Ent_UNIVASF_3

Embora os cursos tradicionais de formação de professores ou formação inicial presencial não prevejam a capacitação docente para atuar na EAD, Gilberto (2013) salienta que a fim de suprir essa lacuna na formação e ter capacidade de exercer as funções nos cursos a distância, muitos professores têm buscado, por conta própria, adquirir competências e imergir na compreensão de novos saberes necessários ao exercício da profissão.

Então, fui procurando por mim, procurando na própria instituição para ver o que é que tinha, procurando com outros colegas que deram a mesma disciplina que eu, e dali tirar alguma coisa, aperfeiçoar. E aí eu fui conseguindo desenvolver algumas competências para trabalhar na EAD.

Ent_UNIVASF_5

Particularmente, é autodidata. É indo buscar. O que a gente trabalha hoje em dia de ambiente, por exemplo, o moodle, se a gente pegar a nossa estrutura atual da secretaria, já existem versões mais novas do moodle, com muito mais facilidade de uso, e a gente ainda está usando uma versão mais antiga. Então, eu, particularmente, fui buscar autodidata, buscar só. Infelizmente a gente ainda está nesta condição.

Ent_UNIVASF_10

Dessa maneira, a universidade como um todo tem que permitir e, especialmente, viabilizar o desenvolvimento de competências dos seus membros individuais, alertam Schneckenberg e Wildt (2006), se quiser agir estrategicamente no campo da inovação das TICs. Os autores alertam ainda que existe uma forte relação e interdependência entre o nível individual e organizacional no desenvolvimento de competências.

\section{CONSIDERAÇÕES FINAIS}

Do estudo da literatura conclui-se que, quando a profissão do professor passa a ser compreendida enquanto práticas associadas ao ato de ensinar, essa adquire características específicas (e distintas) de quaisquer outras atividades e/ou funções desempenhadas pelos professores do ensino superior, demandando, portanto, competências próprias e diferenciadas para tal. Ao se considerar, entretanto, o novo contexto educacional estabelecido pelo avanço tecnológico, pelo estímulo ao uso das TICs e pela consolidação da EAD, acredita-se ser de fundamental importância a consideração de competências tecnológicas no exercício da profissão docente. Nesse sentido, a competência eletrônica deve ser compreendida como uma competência para a ação específica de professores para dominar as tecnologias de 
aprendizagem. Sua aquisição requer mais do que aprender respectivamente novos conhecimentos, desenvolver novas competências ou a assumir novas atitudes.

Assim, os professores além de reforçarem as competências que já possuem, precisam, também, adquirir novas competências que lhes permitam conhecer e julgar por que, quando e como utilizar as TIC na educação. Isso porque a EAD em muito difere no tempo e espaço da tradicional educação presencial, e o professor passa a ser um mediador no acesso à informação durante o processo de ensino-aprendizagem, exigindo novas competências docentes, uma vez que precisa ser sensibilizado e preparado para utilizar todo o potencial educativo das tecnologias disponíveis para a EAD e, assim, provavelmente, novos saberes deverão ser construídos.

Nesse sentido, faz-se necessário compreender que a dinâmica do processo ensinoaprendizagem, quando intermediada pelas TICs, difere quando comparada com a modalidade presencial, especialmente com relação aos papéis e às competências do professor e, também dos alunos, à nova realidade da sala de aula (que passa a ser virtual, interativa e tecnológica) e a um novo currículo no contexto de aprendizagem aberta. A eficiência desse processo (de ensino-aprendizagem) depende diretamente do ambiente de aprendizagem em que professores e alunos estão situados que, por sua vez, depende em grande parte do ajuste das competências dos docentes neste cenário.

Sugere-se, para pesquisas futuras, a análise do contexto organizacional em que as necessidades e desafios específicos, sobre o uso das TICs, são definidos e em que a competência individual é desenvolvida, analisando a interferência das condições institucionais das Instituições de Ensino Superior no desenvolvimento de competências eletrônicas dos professores.

\section{REFERÊNCIAS}

ARRUDA, Heloisa Paes de Barros. Entre o presencial e o virtual: a videoconferência, sentimentos e emoções implicados. In: BEHRENS, Marilda Aparecida; ENS, Romilda Teodora; VOSGERAU, Dilmeire Sant'Anna Ramos. Discutindo a educação na dimensão da práxis. Curitiba: Champagnat, 2007.

BANDEIRA-DE-MELLO, Rodrigo. Softwares em pesquisa qualitativa. In: GODOI, Christiane Kleinübing; BANDEIRA-DE-MELLO, Rodrigo; SILVA, Anielson Barbosa.

Pesquisa qualitativa em estudos organizacionais: paradigmas, estratégias e métodos. São Paulo: Saraiva, 2006. 
BARBOSA, Maria de Fátima S. O.; REZENDE, Flávia. A prática dos tutores em um programa de formação pedagógica a distância: avanços e desafios. Interface, v.10, n.20, p.473-486, 2006.

BARDIN, L. Análise de Conteúdo. São Paulo: Edições 70, 2011.

BAUER, Martin W.; AARTS, Bas. A construção do corpus: um princípio para coleta de dados qualitativos. In: BAUER, M. W.; GASKELL, G. Pesquisa qualitativa com texto imagem e som: um manual prático. Petrópolis: Vozes, 2002.

BERAZA, Miguel. A. Zalbaza. Uma nova didáctica para o ensino universitário: respondendo ao desafio do espaço europeu de ensino superior. Texto para Sessão Solene comemorativa do Dia da Universidade, por ocasião do $95^{\circ}$ aniversário da Universidade do Porto. Porto: Universidade do Porto, 2006.

BRASIL. Referenciais de qualidade para a modalidade de educação superior a distância. Brasília: MEC, 2007.

CAELLI, Kate; RAY, Lynne; MILL, Judy. Clear as Mud: Toward Greater Clarity in Generic Qualitative Research. International Journal of Qualitative Methods, v. 2, n. 2, p. 1-13, 2003.

CASSUNDÉ, Fernanda Roda; CASSUNDÉ JUNIOR, Nildo. O estado do conhecimento sobre educação a distância (EAD) em Administração: por onde caminham os artigos? Fórum temático - oportunidades e desafios das práticas e da gestão de ensino de Administração a distância. Revista Gestão e Planejamento, Salvador, v. 13, n. 2, p. 366-380, maio/ago. 2012.

CUNHA, M. I. Universidade e Pesquisa: Ensaio do futuro. In: LINHARES, C., FAZENDA, I. \& TRINDADE, V. Os Lugares dos Sujeitos na Pesquisa Educacional. Campo Grande, MS: Ed. UFMS, 2001.

FORMIGA, Marcos. A terminologia da EAD. In: LITTO, Frederic M.; FORMIGA, Marcos. Educação a distância: o estado da arte. São Paulo: Pearson, 2009.

GODOY, Arilda Schmidt. Pesquisa qualitativa: tipos fundamentais. Revista de Administração de Empresas, São Paulo, v.35, n.3, p.20-29, Maio/Jun. 1995.

GILBERTO, Irene Jeanete Lemos. A educação a distância no ensino superior e a lógica das competências. Revista Gestão Universitária na América Latina, v.6, n.1, p.273-286, jan. 2013.

GODOI, Christiane Kleinübing; MATTOS, Pedro Lincoln Carneiro Leão. Entrevista qualitativa: instrumento de pesquisa e evento dialógico. In: GODOI, Christiane Kleinübing; BANDEIRA-DE-MELLO, Rodrigo; SILVA, Anielson Barbosa. Pesquisa qualitativa em estudos organizacionais: paradigmas, estratégias e métodos. São Paulo: Saraiva, 2006.

GODOY, Arilda Schmidt. Refletindo sobre critérios de qualidade da pesquisa qualitativa. Gestão.Org, v.3, n.2, mai./ago. 2006. 
HARRY, K.; DESMONDD, K.; JOHN, M. H. Distance education: new perspectives. Routledge Studies in distance education. New York, NY: Routledge, 2006.

Jakobsdóttir, Sólveig; McKeown, Lindy; HOVEN, Debra. Using the new information and communication technologies for the continuing professional development of teachers through open and distance learning. In: DANAHER, Patrick Alan; UMAR, Abdurrahman. Teacher education through open and distance learning. Vancouver: Commonwealth learning, 2010.

LATCHEN, Colin. Using ICT to train teachers in ICT. In: DANAHER, Patrick Alan; UMAR, Abdurrahman. Teacher education through open and distance learning. Vancouver: Commonwealth learning, 2010.

LAVILLE, Christian; DIONNE, Jean. A construção do saber: manual de metodologia da pesquisa em ciências humanas. Porto Alegre: Artmed, 1999.

MAIETTA, Raymond C. Computer-assisted data analysis. In: GIVEN, Lisa M. The Sage Encyclopedia os Qualitative Research Methods. California: SAGE Publications, 2008.

MARTINS, Onilza Borges. Os caminhos da EAD no Brasil. Revista Diálogo Educacional, Curitiba, v.8, n.24, p.357-371, maio/ago. 2008.

MATTAR, João. Interatividade e aprendizagem. In: LITTO, Frederic M.; FORMIGA, Marcos. Educação a distância: o estado da arte. São Paulo: Pearson, 2009.

MENDONÇA, José Ricardo Costa; PAIVA, Kely César Martins; PADILHA, Maria Auxiliadora; BARBOSA, Milka Alves Correia. Competências Profissionais de Professores do Ensino Superior no Brasil: proposta de um modelo integrado. In: 2. ${ }^{a}$ Conferência do FORGES - Fórum da Gestão do Ensino Superior nos Países e Regiões de Língua Portuguesa, 2012, Macau, China. Por um Ensino Superior de Qualidade nos Países e Regiões de Língua Portuguesa, 2012a.

MENEZES, Luis Carlos. Universidade sitiada: A ameaça de liquidação da universidade brasileira. São Paulo: Fundação Perseu Abramo, 2001.

MERRIAM, Sharan B. Qualitative Research and Case Study Applications in Education. San Francisco: Jossey-Bass, 1998.

Qualitative research in practice: examples for discussion and analysis. San Francisco: Jossey-Bass, 2002.

MOORE, Michael; KEARSLEY, Greg. Educação a distância: uma visão integrada. São Paulo: Cengage Learning, 2011.

MOZATTO, A. R.; GRZYBOVSKI, D. Análise de Conteúdo como Técnica de Análise de Dados Qualitativos no Campo da Administração: Potencial e Desafios. Revista de Administração Contemporânea, v. 15, n. 4, p. 731-747, 2011.

PADILHA, Maria Auxiliadora Soares; HELAL, Diogo Henrique; MENDONÇA, José Ricardo Costa. Educação a distância em Administração: olhares sobre as pesquisas, vivências 
e perspectivas. Fórum temático - oportunidades e desafios das práticas e da gestão de ensino de Administração a distância. Revista Gestão e Planejamento, Salvador, v. 13, n. 2, p. 356365, maio/ago. 2012.

PAIVA, Kely Cesar Martins. Gestão de competências e a profissão docente: um estudo em universidades no estado de Minas Gerais. 2007. Tese (Doutorado) - Programa de PósGraduação em Administração, Universidade Federal de Minas Gerais, Belo Horizonte, 2007.

PAIVA, Kely César Martins; BARROS, Valéria Rezende Freitas; MENDONÇA, José Ricardo Costa; SANTOS, Andreia de Oliveira; DUTRA, Michelle Regina Santana. Competências Docentes -Ideais e Reais- em Educação a Distância no Curso de Administração: um estudo em uma instituição brasileira. Anais do TMS Management Studies International Conference - Algarve 2012, Universidade do Algarve, Portugal, 2012.

RAMOS, Marise Nogueira. A pedagogia das competências: autonomia ou adaptação? São Paulo: Cortez, 2002.

RIBEIRO, Luis Otoni Meireles; TIMM, Maria Isabel; ZARO, Milton Antonio. Gestão de EAD: a importância da visão sistêmica e da estruturação dos CEADs para a escolha de modelos adequados. CINTED-UFRGS. v. 5. n. 1, Jul. 2007.

SANAVRIA, Claudio Zarate. Avaliação da aprendizagem à distância: concepções e práticas de professores no ensino superior. 2008. Dissertação (Mestrado) - Programa de PósGraduação em Educação, Universidade Católica Dom Bosco, Campo Grande, 2008.

SCHNECKENBERG, Dirk. eCompetence Development Measures for Faculty in Higher Education - A Comparative International Investigation. Tese. Fachbereich Bildungswissenschaften der Universität Duisburg-Essen. Standort Essen, 2007.

. Ecompetence in european higher education: ICT policy goals, change processes and research perspectives. In: MAC LABHRAINN, I.; MCDONALD LEGG, C.; SCHNECKENBERG, D.; WILDT, J. The Challenge of eCompetence in Academic Staff Development. Galway: CELT, 2006.

El e-learning transforma la educación superior. Educar, n.33, p.143-156, 2004.

Face the Human Factor: The Role of eCompetence in the Future of Higher Education. In: NUNES, M.B.; McPHERSON, M. International Association for Development of the Information Society: Multi-Conference on Computer Science and Information Systems, 22-27 July, p.98-105, 2008a.

Overcoming barriers for eLearning in universities: portfolio models for eCompetence development of faculty. British Journal of Educational Technology, v.41, n.6, p.979-991, 2010a.

What is e-Competence? Conceptual Framework and Implications for Faculty Engagement. In: EHLERS, Ulf-Daniel; Schneckenberg, Dirk. Changing Cultures in Higher Education: Moving Ahead to Future Learning. New York: Springer International, 2010b. 
Schneckenberg, Dirk; Wildt, Johannes. Understanding the concept of ecompetence for academic staff. In: Labhrainn, Mac; LEGG, McDonald; Schneckenberg, Dirk; WILDT, Johannes. The Challenge of eCompetence in Academic Staff Development. Galway: CELT, 2006.

Schönwald, Ingrid. Sustainable implementation of e-learning as a change process at universities. St. Gallen, Switzerland: Swiss Centre for Innovations in Learning, 2003.

SILVA, Maria Aparecida; LIMA FILHO, Dario de Oliveira; RIBEIRO, Silvar; CASTANHA, Anderson. Projeto Pedagógico do curso de Especialização em Gestão Pública. MEC: Brasil, 2012.

SOUZA, Alba Regina Battisti; SARTORI, Ademilde Silveira; ROESLER, Jucimara. Mediação pedagógica na educação a distância: entre enunciados teóricos e práticas construídas. Revista Diálogo Educacional, Curitiba, v.8, n.24, p.327-339, maio/ago. 2008.

STALMEIER, Marjo. Ecompetence profiles: an instrument for ecompetence management. In: Labhrainn, Mac; LEGG, McDonald; Schneckenberg, Dirk; WILDT, Johannes. The Challenge of eCompetence in Academic Staff Development. Galway: CELT, 2006.

STAKE, Robert E. Qualitative case studies. In: DENZIN, Norman K.; LINCOLN, Yonna S. Handbook of qualitative research. 3rd. ed. California: Sage Publications, 2005.

TIGELLAR, Dineke E. H.; DOLMANS, Diana H. J. M.; WOLFHAGE, Ineke H. A. P.; VAN DER VLEUTEN, Cees p. M. The development and validation of a framework for teaching competencies in higher education. Higher education, 48, p.253-268, 2004.

TORRES, Patrícia Lupion; MARRIOTT, Rita de Cássia Veiga; MATOS, Elizete Lúcia Moreira. Mediação pedagógica com o uso de mapas conceituais em ambiente virtual de aprendizagem. In: ENS, Romilda Teodora; BEHRENS, Marilda Aparecida; VOSGERAU, Dilmeire Sant'Anna Ramos. Trabalho do professor no espaço escolar. Curitiba: Champagnat, 2009.

VOLK, Benno; KELLER, Stefan Andreas. The «Zurich E-Learning Certificate» A role model for the acquirement of eCompetence for Academic Staff and an example of a practical implementation. European Journal of Open, Distance and E-Learning, p.1-8, 2010.

Wheeler, Steve. Open Content, Open Learning 2.0: Using Wikis and Blogs in Higher Education. In: EHLERS, Ulf-Daniel; Schneckenberg, Dirk. Changing Cultures in Higher Education: Moving Ahead to Future Learning. New York: Springer International, 2010.

WROBEL, Julia Schaetzle; CARNEIRO, Teresa Cristina Janes; PALMA, Waneide de Sousa; AGUIAR, Lemuel Brasil. Tutoria em educação a distância: teoria, prática, aprendizados e desafios. Administração: Ensino e Pesquisa, Rio de Janeiro, v.11, n.3, p.331-354, Jul/Ago/Set 2010. 